\title{
Rational design of photocatalysts for ammonia production from water and nitrogen gas
}

\author{
Seokwoo Choe ${ }^{1}$, Sung Min Kim', Yeji Lee ${ }^{1}$, Jin Seok ${ }^{1}$, Jiyong Jung ${ }^{1}$, Jae Sung Lee ${ }^{2^{*}}$ and Youn Jeong Jang ${ }^{1^{*}}$ (i)
}

\begin{abstract}
Photocatalytic $\mathrm{N}_{2}$ reduction has emerged as one of the most attractive routes to produce $\mathrm{NH}_{3}$ as a useful commodity for chemicals used in industries and as a carbon-free energy source. Recently, significant progress has been made in understanding, exploring, and designing efficient photocatalyst. In this review, we outline the important mechanistic and experimental procedures for photocatalytic $\mathrm{NH}_{3}$ production. In addition, we review effective strategies on development of photocatalysts. Finally, our analyses on the characteristics and modifications of photocatalysts have been summarized, based on which we discuss the possible future research directions, particularly on preparing more efficient catalysts. Overall, this review provides insights on improving photocatalytic $\mathrm{NH}_{3}$ production and designing solar-driven chemical conversions.
\end{abstract}

Keywords: Photocatalyst, Ammonia, Nitrogen

\section{Introduction}

Recently, there has been an increasing focus on ammonia $\left(\mathrm{NH}_{3}\right)$ as not only a key commodity for chemicals widely used in industries [1,2], but also as a liquid energy carrier [3] that enables transport and supply of hydrogen $\left(\mathrm{H}_{2}\right)$ gas through cracking. Furthermore, $\mathrm{NH}_{3}$ is an alternative carbon-free energy source that can be utilized in energyconversion devices, for example, direct $\mathrm{NH}_{3}$ fuel cells [4, 5]. Traditionally, $\mathrm{NH}_{3}$ production has mainly relied on the Haber-Bosch process, which is energy intensive and generates considerable volume of $\mathrm{CO}_{2}$ into the atmosphere because of these requirements, along with the needs for $\mathrm{H}_{2}$ and the extreme operation condition [6].

Photochemical $\mathrm{NH}_{3}$ production using $\mathrm{N}_{2}$ and water as a hydrogen source at ambient temperature and pressure can offer a promising alternative route that is less energy

\footnotetext{
*Correspondence: jlee1234@unist.ac.kr; yjang53@hanyang.ac.kr ${ }^{1}$ Department of Chemical Engineering, Hanyang University, 222 Wangsimni-ro, Seongdong-gu, Seoul 04763, Republic of Korea ${ }^{2}$ Department of Energy and Chemical Engineering, Ulsan National Institute and Science and Technology, 50, UNIST-gil, Ulsan 44919, Republic of Korea
}

intensive and reduces $\mathrm{CO}_{2}$ emission, thereby significantly reducing environmental concerns [7]. $\mathrm{NH}_{3}$ production paired with water oxidation is a thermodynamically uphill reaction; therefore, external energy input is necessary [8]. Photocatalysts can utilize solar energy, which is supplied to Earth with sufficient solar power and abundance and facilitate $\mathrm{NH}_{3}$ production. Since $\mathrm{TiO}_{2}$ photocatalysts applied to $\mathrm{N}_{2}$ reduction, new photocatalysts and their modifications have been intensively suggested to improve photocatalytic $\mathrm{NH}_{3}$ production [9].

Major advances in metal oxides such as $\mathrm{TiO}_{2}, \mathrm{WO}_{3}$, and $\mathrm{SrTiO}_{3}$, bismuth oxyhalides, and polymeric carbon nitride photocatalysts have resulted in interests in the development of photocatalysts and their applications for $\mathrm{NH}_{3}$ production [10-14]. This review is composed of mainly two sections: (1) fundamentals for photocatalytic $\mathrm{NH}_{3}$ production, (2) strategies to develop photocatalysts. The first section focuses on the principles and mechanisms involved in the overall photocatalytic reaction. The second section contains recent progresses in the development of catalysts and their major advantages with regard to catalytic performance. The insights and discussions 
provided in this review will serve as useful resources for further development of photocatalysts and provide future research direction for photocatalytic $\mathrm{NH}_{3}$ production.

\section{Fundamentals for photocatalytic $\mathrm{NH}_{3}$ production 2.1 Principle and mechanism}

$\mathrm{NH}_{3}$ production by $\mathrm{N}_{2}$ reduction $\left(\mathrm{N}_{2}(\mathrm{~g})+6 \mathrm{H}^{+} \quad+6 \mathrm{e}^{-} \rightleftharpoons 2 \mathrm{NH}_{3}(\mathrm{~g}), \quad \mathrm{E}^{0}=0.092 \quad \mathrm{~V} \quad\right.$ vs. SHE) paired with $\mathrm{O}_{2}$ production by water oxidation $\left(2 \mathrm{H}_{2} \mathrm{O}(\mathrm{l}) \rightleftharpoons \mathrm{O}_{2}(\mathrm{~g})+4 \mathrm{H}^{+}+4 \mathrm{e}^{-}, \mathrm{E}^{0}=1.229 \mathrm{~V}\right.$ vs. SHE $)$ is a thermodynamically uphill reaction that requires a potential of at least $1.137 \mathrm{eV}$ [15] per electron [16]. Moreover, three electrons are required to produce an $\mathrm{NH}_{3}$ molecule, and four holes are required to produce an $\mathrm{O}_{2}$ molecule according to eqns. (1) and (2):

Absorption of light :

photocatalyst $+h v\left(>E_{\mathrm{g}}\right) \rightarrow e_{\mathrm{CB}}^{-}+\mathrm{h}_{\mathrm{VB}}^{+}$

Nitrogen reduction (NRR) : $\mathrm{N}_{2}+6 \mathrm{H}^{+}+6 \mathrm{e}_{\mathrm{CB}}^{-} \rightarrow 2 \mathrm{NH}_{3}$

Water oxidation (OER) : $2 \mathrm{H}_{2} \mathrm{O}+4 \mathrm{~h}_{\mathrm{VB}}^{+} \rightarrow \mathrm{O}_{2}+4 \mathrm{H}^{+}$

A simplified schematic diagram for photocatalyic $\mathrm{NH}_{3}$ production and challenges in designing photocatalysts are summarized in Fig. 1. For overall $\mathrm{NH}_{3}$ production, photons with energies $>1.137 \mathrm{eV}$ are required to generate photoexcited electron-hole pairs that carry out the desired redox reactions at the active sites on the surfaces of the photocatalysts. Thus, a photocatalyst must have an energy band gap, $\left(E_{g}=E_{C B M}-E_{V B M}\right.$, where CBM and VBM represent conduction band minimum and valence band maximum), larger than the energy required for the overall $\mathrm{NH}_{3}$ production. In addition, a photocatalyst must have a suitable conduction and valence band alignment to drive two half-reactions using photoexcited electrons $\left(\mathrm{e}^{-}\right)$and holes $\left(\mathrm{h}^{+}\right)$under solar light irradiation.

The major factors to consider for photocatalyst designs are (1) photon absorption followed by photoexcited carrier generation, (2) their migration and separation, and (3) their consumption by redox reactions on the surfaces of photocatalysts. The dominant photon energy spectrum obtained from the sunlight is in the range of 390-700 nm. Furthermore, because photocatalytic redox reactions require kinetic overpotentials, photocatalysts have a bandgap energy in the range of $1.6-2.4 \mathrm{eV}$. The generated photoexcited carriers can migrate to active sites on the surface where redox reactions carried out. However, since the kinetics of carrier recombination in the interiors of the photocatalysts is fast, considerable amounts of photoexcited carriers are recombined [17]. Moreover, photoexcited carriers can be trapped in the interior and surface of the photocatalyst, which causes photocorrosion. Thus, a photocatalyst design to improve electron-hole pair migration and separation is important for further development of photochemical $\mathrm{NH}_{3}$ production [18].

Most semiconductors that act as light absorbers in photocatalysts are inactive in the redox reactions with the photoexcited carriers; thus, the active sites on the surface of semiconductor are decorated with cocatalysts [19]. For example, cocatalysts, such as $\mathrm{RuO}_{\mathrm{x}}, \mathrm{CoO}_{\mathrm{x}}$, and Co-pi [20-22], combined on the surface of the semiconductor for facile water oxidation by providing active sites. Another critical point to note in $\mathrm{NH}_{3}$ production via photochemical $\mathrm{N}_{2}$ reduction is the facile competitive hydrogen evolution reaction by water reduction. $\mathrm{NH}_{3}$ production is kinetically much more complex than water reduction, although the thermodynamic requirements for those reactions are similar [23]. This indicates that photochemical $\mathrm{H}_{2}$ production may be predominant, resulting in inactive $\mathrm{NH}_{3}$ production. Thus, it is critical to modify the surface that provides active sites for the desired redox reaction using suppressing competitive reactions on the semiconductors.

It is also necessary to note the importance of rate balance for photocatalytic reactions on photocatalysts. Since electrons and holes are generated in pairs under illuminations, their consumption must be coupled as well. For instance, if oxidation reactions involving photogenerated holes are sluggish, the total $\mathrm{NH}_{3}$ production rate should be similar. In this case, scavengers, such as ethanol, methanol, and sulfites, can be employed as sacrificial reagents to facilitate oxidation reaction using photoexcited holes, thereby preventing from photoexcited carrier recombination [24]. However, since scavengers may interfere with counter reactions, here $\mathrm{N}_{2}$ reduction, or product evaluation methods, the target scavenger should be chosen carefully. It is discussed in detail in the next section.

\subsection{Experimental process}

The simplest photocatalytic $\mathrm{NH}_{3}$ production set-up is a particulate PC system where photocatalysts are dispersed in a medium, typically pure water, with $\mathrm{N}_{2}$ bubbling under simulated solar light illumination, as shown in Fig. 1 b. $\mathrm{NH}_{3}$ and $\mathrm{O}_{2}$ are generated on a single photocatalyst. The produced $\mathrm{NH}_{3}$ is technically evaluated by the spectrophotometric method via the indophenol blue method or quantified using proton nuclear magnetic resonance spectroscopy $\left({ }^{1} \mathrm{H}-\mathrm{NMR}\right)$ with isotope labeled nitrogen ${ }^{15} \mathrm{~N}$ as shown in Fig. 2.

The indophenol blue method is based on the principle of the Berthelot reaction, where typically, salicylic acid, citrate, hypochlorite, and ferricyanide are used in 
a
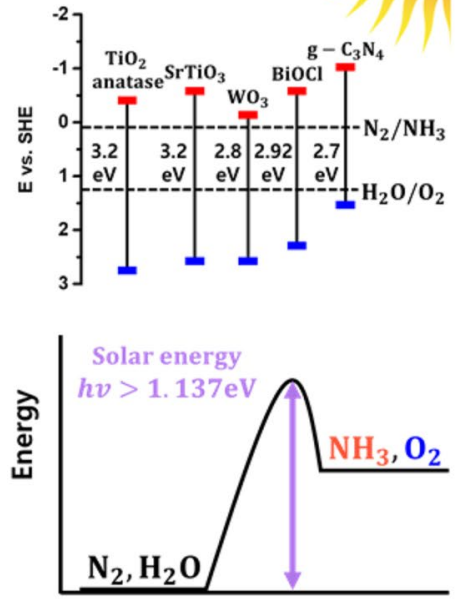

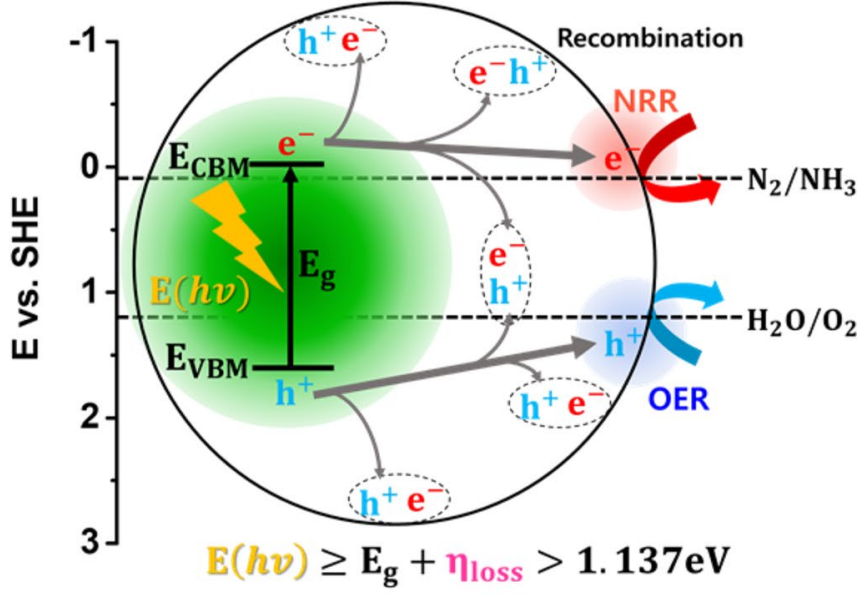

$\eta_{\text {loss }}=\eta_{\text {resistance }}+\eta_{\text {oER }}+\eta_{\text {NRR }}$

b

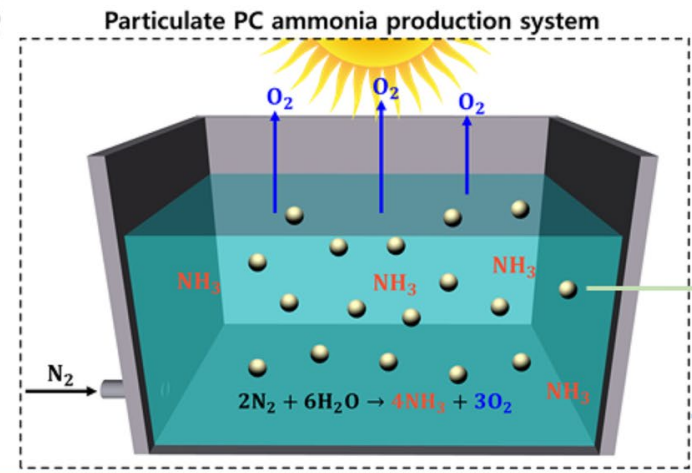

Strategies for catalyst modification

1. Heteroatom doping

2. Vacancy formation

3. Composite formation

4. Surface modification

Challenges for photocatalytic $\mathrm{NH}_{3}$ production

1. Limited photon absorption

2. Fast charges recombination

3. Limited charges separation

4. Slow redox reactions

Strategies for system engineering

1. Reaction control

2. Environment optimization

Fig. 1 a The schematic illustration of photochemical nitrogen reduction reaction [15]. b The challenges and strategies for photocatalytic $\mathrm{NH}_{3}$ production in particulate photocatalytic (PC) ammonia production system

an alkaline solution. In the presence of $\mathrm{NH}_{4}{ }^{+}$, the color of the yellowish indicating solution, which contains the reagents, turns to blue, corresponding to $655 \mathrm{~nm}$. As shown in Fig. 2a and b, thus, the concentration of $\mathrm{NH}_{3}$ can be quantified by measuring the absorbance change at $655 \mathrm{~nm}$ using a UV-Vis spectrophotometer [28]. However, to quantify the concentration of $\mathrm{NH}_{3}$ generated by photocatalytic $\mathrm{N}_{2}$ reduction, multiple possible contaminants that interfere with the evaluation should be fully controlled [28]. For example, methanol, a widely used as a hole scavenger, and its derivatives cause incorrect color changes and significantly decrease the accuracy of $\mathrm{NH}_{3}$ quantification as shown in Fig. 2c and d. Another critical point for $\mathrm{NH}_{3}$, which is photocatalytically produced, quantification is to eliminate the parts from $\mathrm{NH}_{3}$ contaminants, unintentionally present introduced through catalyst, components in set-up [26] or even the air. In fact, $\mathrm{NH}_{3}$ present in human breath, sanitizers, and so can rapidly accumulate in water [29].

The most rigorous procedure to quantify photocatalytically generated $\mathrm{NH}_{3}$ from $\mathrm{N}_{2}$ reduction is to use isotope labeled ${ }^{15} \mathrm{~N}_{2}$ gas. The photocatalytic reactions are conducted in a simple particulate system with ${ }^{15} \mathrm{~N}_{2}$ 

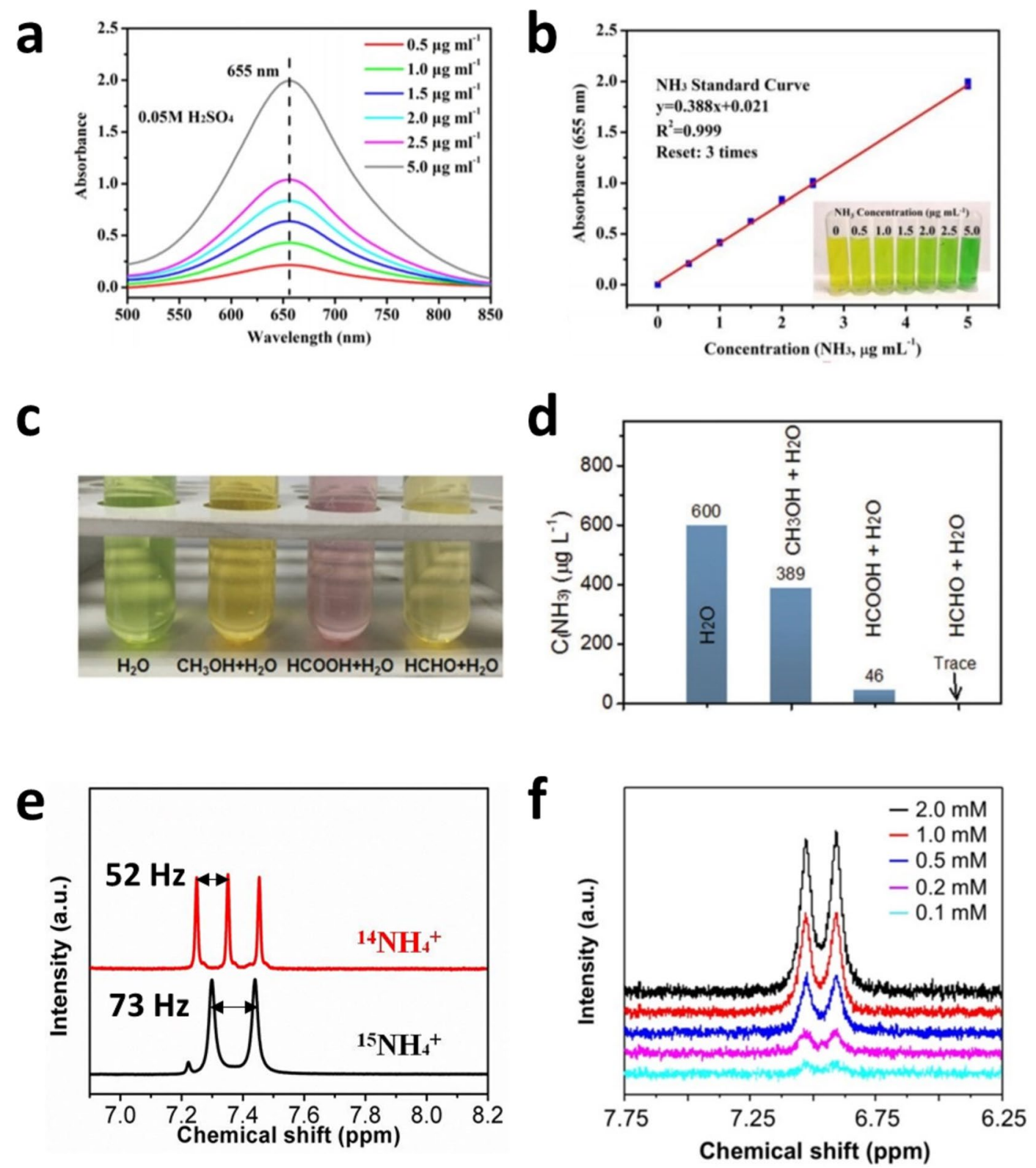

Fig. 2 a Spectrum and $\mathbf{b}$ standard curve of UV-Vis spectrophotometer with standard solutions from 0.5 to $5.0 \mu \mathrm{gg} \cdot \mathrm{mL}^{-1}$ in $0.05 \mathrm{M} \mathrm{H}_{2} \mathrm{SO}_{4}$. Reproduced with permission [25]. Copyright 2019, PNAS. c, d Interference impact on measurements of produced $\mathrm{NH}_{3}$ in solution with $\mathrm{CH}_{3} \mathrm{OH}$, $\mathrm{HCOOH}$ and $\mathrm{HCHO}$. Reproduced with permission [26]. Copyright 2019, Wiley-VCH. e ${ }^{1} \mathrm{H}-\mathrm{NMR}$ spectrums of ${ }^{14} \mathrm{NH}_{4}{ }^{+}\left(\right.$red) and ${ }^{15} \mathrm{NH}_{4}{ }^{+}(\mathrm{black})$, respectively. Reproduced with permission [27]. Copyright 2021, The Royal Society of Chemistry. fThe peaks for ${ }^{14} \mathrm{NH}_{4}{ }^{+}$corresponding to its concentration. Reproduced with permission [8]. Copyright 2020, American Chemical Society

bubbling. Since the splitting of ${ }^{1} \mathrm{H}$ resonance in ${ }^{15} \mathrm{NH}_{4}{ }^{+}$ and ${ }^{14} \mathrm{NH}_{4}{ }^{+}$resulting from the difference in the scalar interaction between $\mathrm{N}\left({ }^{15} \mathrm{~N}\right.$ or $\left.{ }^{14} \mathrm{~N}\right)$ and $\mathrm{H}$ is differentiated, the ${ }^{15} \mathrm{NH}_{4}{ }^{+}$produced, which is dissolved in an aqueous reacting solution, can be quantified by ${ }^{1} \mathrm{H}-\mathrm{NMR}$ [30]. For instance, the ${ }^{1} \mathrm{H}$ resonance in ${ }^{15} \mathrm{NH}_{4}{ }^{+}$can be split into two symmetric signals with a spacing of $73 \mathrm{~Hz}$, whereas the resonance in ${ }^{14} \mathrm{NH}_{4}{ }^{+}$can be split into three symmetric signals with a spacing of $52 \mathrm{~Hz}$ as shown in Fig. 2e. Thus, false positive evaluations for the produced $\mathrm{NH}_{3}$ can be prevented effectively.

\section{Strategies to develop photocatalysts}

This section is divided into mainly two parts: (1) semiconductors comprising photocatalysts, which have been widely applied as a light absorber in Fig. 3a, and (2) 


\section{a}

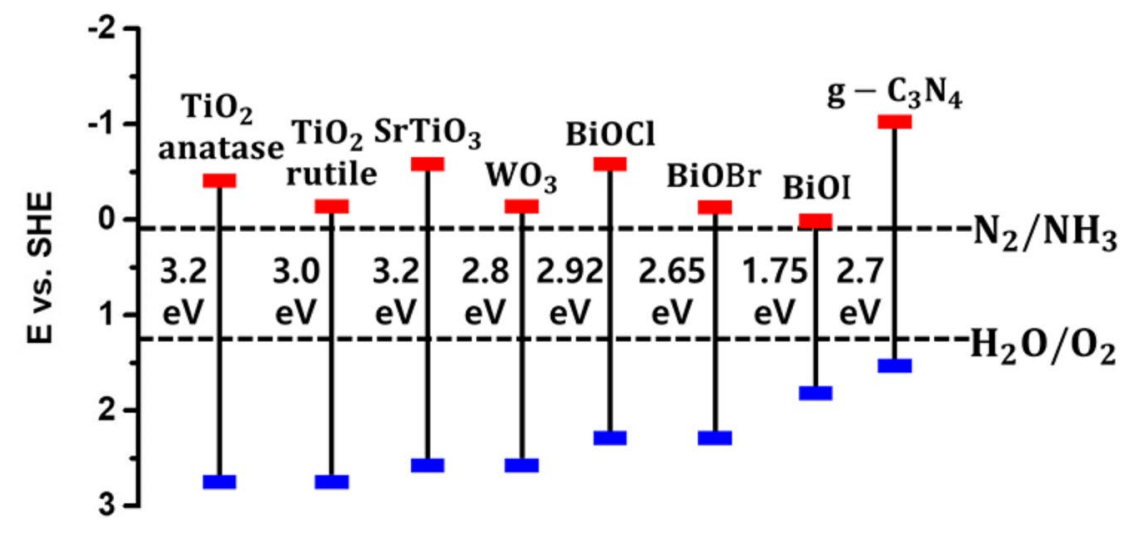

b

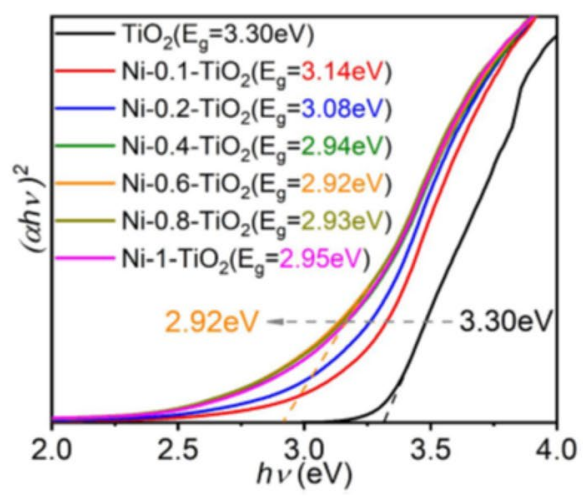

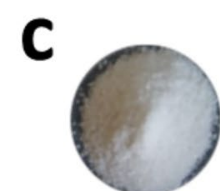
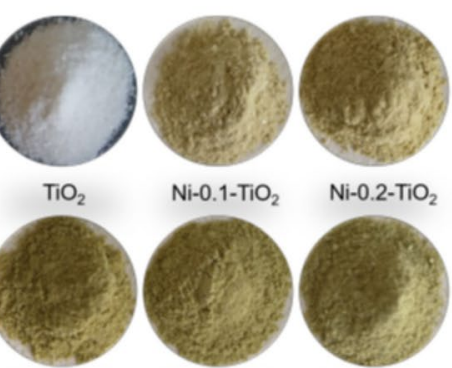

$\mathrm{Ni}-0.6-\mathrm{TiO}_{2}$
$\mathrm{Ni}-0.1-\mathrm{TiO}_{2}$

$\mathrm{Ni}-0.2-\mathrm{TiO}_{2}$
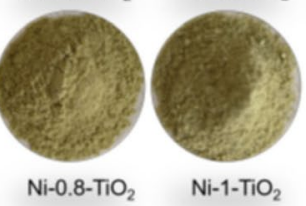

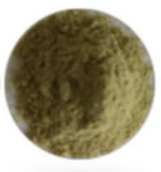

Ni-0.4- $\mathrm{TiO}_{2}$

d
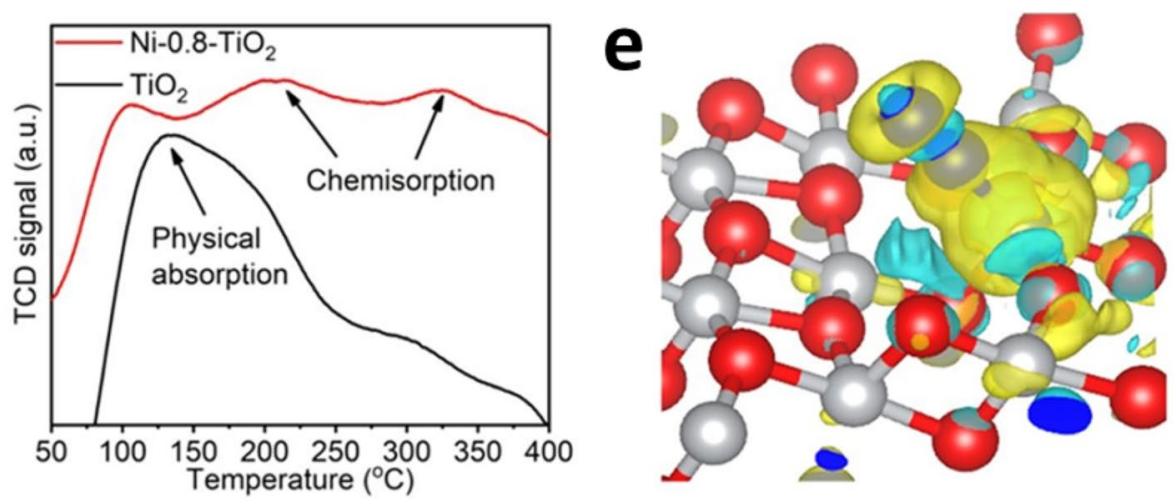

Fig. 3 a The band alignments of widely used photocatalysts. $\mathbf{b}$ The Tauc plot $(a h v)^{2}$ versus ( $h v$ ) for the caluate the optical band gap energy $\mathrm{E}_{\mathrm{g}}$.

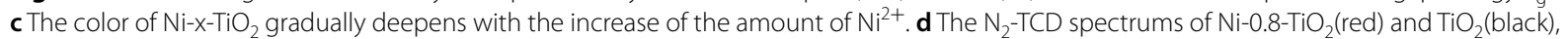

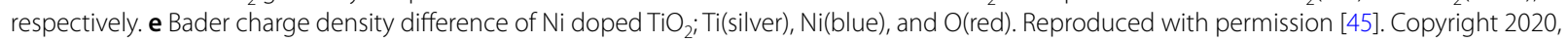
Americal Chemical Society

strategies to modify the catalysts, which have been effectively used to further increase the photocatalytic $\mathrm{NH}_{3}$ production.

\subsection{Semiconductors}

Titanium(Ti)-based oxides Titanium dioxide, $\mathrm{TiO}_{2}$, possesses several advantages that make it attractive for use in photocatalytic $\mathrm{NH}_{3}$ production. $\mathrm{TiO}_{2}$ has a bandgap of $\sim 3.2 \mathrm{eV}$, which absorbs UV light, and a CBM and
VBM that offer sufficient overpotential for the photoexcited electrons to reduce $\mathrm{N}_{2}$ to $\mathrm{NH}_{3}$ and holes to oxidize water to $\mathrm{O}_{2}$, respectively. In addition, the inexpensive, environmentally benign, and stable nature of $\mathrm{TiO}_{2}$ is an additional advantage. Historically, the primary limitation of using $\mathrm{TiO}_{2}$ has been rapid photoexcited electron-hole recombination, which is similar to many other oxidebased photocatalysts. Strontium titanate, $\mathrm{SrTiO}_{3}$ [31], is another candidate showing two major benefits over 
$\mathrm{TiO}_{2}$ for use in the $\mathrm{NH}_{3}$ production. The $\mathrm{CBM}$ of $\mathrm{SrTiO}_{3}$ is slightly more negative than that of $\mathrm{TiO}_{2}$, thereby providing a stronger driving force to reduce $\mathrm{N}_{2}$ using the photoexcited electrons. In addition, intrinsic charge mobility in $\mathrm{SrTiO}_{3}$ is higher than that in $\mathrm{TiO}_{2}$, thereby suppressing photoexcited charge recombination [32]. However, despite this thermodynamic advantage, the photocatalytic $\mathrm{NH}_{3}$ production using $\mathrm{TiO}_{2}$ or $\mathrm{SrTiO}_{3}$ is limited because of ineffective light absorption resulting from their wide bandgaps and inactive redox reactions due to the limited active sites on their surface. Recently, many attempts have been made to address these limitations, which include doping, coupling with electrocatalysts (cocatalysts), surface defect engineering, and so on [33-35].

Bismuth oxyhalide (BiOX) $\mathrm{BiOX}(\mathrm{X}=\mathrm{Cl}, \mathrm{Br}$, and $\mathrm{I})$ has a layered structure where bismuth and oxygen layers $(\mathrm{BiOx})$ are connected with halide $(\mathrm{X})$ layers alternatingly via Van der Waals forces [36]. Since the VBM is determined by $\mathrm{O} 2 \mathrm{p}$ and $\mathrm{X} \delta \mathrm{p}(\delta=3,4$, and 5 , corresponding to $\mathrm{X}=\mathrm{Cl}, \mathrm{Br}$, and I, respectively) and the CBM is mainly evaluated by $\mathrm{Bi} 6 \mathrm{p}$, their band alignments and bandgap are varied depending on the element comprising the semiconductors [37]. For example, $\mathrm{BiOCl}, \mathrm{BiOBr}$, and BiOI have bandgap energies of 2.92, 2.65, and $1.75 \mathrm{eV}$, respectively [38], and are thermodynamically suitable for $\mathrm{NH}_{3}$ production, they enable the production of $\mathrm{NH}_{3}$ and $\mathrm{O}_{2}$ by the overall photocatalytic $\mathrm{N}_{2}$ reduction. However, despite these advantages, $\mathrm{BiOX}$ semiconductors have severe drawbacks when using them as photocatalysts, mainly due to the insufficient photogenerated charge separation in the bulk and surface. Recently, their fundamental limitations have been investigated, and strategies to improve their photocatalytic performances have been explored.

Graphitic carbon nitride $\left(\mathrm{g}-\mathrm{C}_{3} \mathrm{~N}_{4}\right)$ g- $\mathrm{C}_{3} \mathrm{~N}_{4}$ is a polymeric semiconductor with a bandgap energy of $2.7 \mathrm{eV}$ and appropriate positions for the CBM and VBM for the $\mathrm{NH}_{3}$ and $\mathrm{O}_{2}$ production, respectively [39]. However, since rapid photoexcited carrier recombination in the bulk results in limited charge separation in the redox reactions and ineffective $\mathrm{N}_{2}$ adsorption on the surface, as an initial step for $\mathrm{N}_{2}$ reduction, multiple advancements to develop g- $\mathrm{C}_{3} \mathrm{~N}_{4}$ have been suggested [40].

\subsection{Strategies to enhance photocatalytic $\mathrm{NH}_{3}$ production}

As described in the introduction section, photocatalysts comprising semiconductors can produce $\mathrm{NH}_{3}$ using $\mathrm{N}_{2}$ and water under illumination. However, the typical $\mathrm{NH}_{3}$ production rate and efficiency of intrinsic semiconductors using solar energy have been far lower than those expected from their bandgap energies. The major limiting factors include (1) limited light absorption because of the intrinsically large bandgaps, (2) significantly fast photoexcited electron-hole pairs recombination, and (3) slow redox reactions including $\mathrm{N}_{2}$ reduction and water oxidation. Recently, many strategies have been made to address one or more of these challenges, which include engineering defects by extrinsic doping or vacancy introducing, composites forming using multi-light absorbers, and coupling with electrocatalysts. This section will give an overview of each of these attempts and discuss how these strategies affected the photocatalytic $\mathrm{NH}_{3}$ production.

\subsubsection{Defect engineering}

Defect engineering has been widely suggested to control bulk and surface properties of catalysts, for example, by heteroatoms doping, vacancies formation, and so on. This defect engineering enhances photocatalytic $\mathrm{NH}_{3}$ production by changing the light absorption properties, improving charge separation efficiencies, or facilitating surface redox reactions, and it generally influences the multi-mechanistic steps of light harvesting simultaneously [41].

Heteroatom doping Heteroatom doping involves intentional introduction of impurity atoms into the lattices of materials to change their optical and electrical properties [42-44]. Depending on the species and degree (concentration) of dopants, changes, in the bandgap energy, band alignment, charge separation efficiency, and $\mathrm{N}_{2}$ adsorption ability are expected. However, since dopants can provide electron-hole recombination sites or prohibit charge transports, identifying types and concentrations of dopants appropriate for the photocatalytic process is important.

Zaicheng Sun and coworkers prepared a nickel-doped $\mathrm{TiO}_{2}\left(\mathrm{Ni}-\mathrm{x}-\mathrm{TiO}_{2}\right.$, where $\mathrm{x}=$ concentration of the Ni precursor controlled in the preparation step) photocatalyst using the sol-gel method [45] show Their optimized sample $\left(\mathrm{Ni}-0.8-\mathrm{TiO}_{2}\right)$ exhibited an $\mathrm{NH}_{3}$ production rate of $46.80 \mu \mathrm{mol} \cdot \mathrm{g}^{-1} \cdot \mathrm{h}^{-1}$ under simulated solar light irradiation, which is seven times higher than the rate using pure reference $\mathrm{TiO}_{2}$. The Ni-0.8- $\mathrm{TiO}_{2}$ sample extends the light absorption range to the visible light region with a bandgap energy of $2.92 \mathrm{eV}$, whereas pure $\mathrm{TiO}_{2}$ absorbs only UV light with a bandgap energy of $3.2 \mathrm{eV}$ as shown in Fig. 3b. As Ni atoms having $2+$ valence that replace the $\mathrm{Ti}$ site having $4+$ valence, oxygen vacancies $(\mathrm{Ov})$ are created naturally for charge neutrality within the host semiconductors, and they vary the band position of the CBM and $\mathrm{VBM}$ in $\mathrm{TiO}_{2}$, which results in a decrease in the bandgap energy. Besides changes in the optical properties, $\mathrm{N}_{2}$ 
adsorption, the initiation step for $\mathrm{NH}_{3}$ production from $\mathrm{N}_{2}$, is enhanced by $\mathrm{Ni}$ doping on $\mathrm{TiO}_{2}$, as investigated using a $\mathrm{N}_{2}$ temperature programmed desorption spectroscopy $\left(\mathrm{N}_{2}\right.$-TPD) and a computational analysis.

Tierui Zhang and coworkers prepared a copper-doped $\mathrm{TiO}_{2}$ nanosheet $\left(\mathrm{x} \%-\mathrm{TiO}_{2}\right.$, where $\mathrm{x}=$ molar ration of $\mathrm{Cu} / \mathrm{Ti}$ controlled in the preparation step) photocatalyst using a hydrothermal method [46]. The optimized sample, $6 \%-\mathrm{TiO}_{2}$, exhibited an $\mathrm{NH}_{3}$ production rate of $78.9 \mu \mathrm{mol} \cdot \mathrm{g}^{-1} \cdot \mathrm{h}^{-1}$, whereas pristine $\mathrm{TiO}_{2}$ nanosheets exhibited a rate of $0.34 \mu \mathrm{mol} \cdot \mathrm{g}^{-1} \cdot \mathrm{h}^{-1}$. As $\mathrm{Cu}$ heteroatoms replaced the sites of $\mathrm{Ti}$ in the $\mathrm{TiO}_{2}$ nanosheets, small amounts of $\mathrm{Ti}^{3+}$ valence states in $\mathrm{Ti}^{4+}$-dominant $\mathrm{TiO}_{2}$ and Ov sites are created, as observed using X-ray photoelectron spectroscopy and X-ray absorption fine structure spectroscopy. Furthermore, owing to the difference in size between the $\mathrm{Cu}^{2+}$ dopants and $\mathrm{Ti}^{4+}$ hosts, $\mathrm{Cu}$ doped $\mathrm{TiO}_{2}$ has a compressive strain, which is evaluated by DFT calculations, and it causes changes in the distribution in the electron densities around $\mathrm{O}$ and $\mathrm{Ti}$ in the materials. The combination of non-stoichiometry and lattice strain in $\mathrm{Cu}$-doped $\mathrm{TiO}_{2}$ narrows its bandgap energy, corresponding to the extended light absorption range of 600-800 nm, and electrons are accumulated around the sites of $\mathrm{O}$ atoms, thereby affecting the changes in the $\mathrm{N}_{2}$ adsorption affinity.

Jing Zhang and coworkers prepared a Fe-doped $\mathrm{SrTiO}_{3} \quad\left(\mathrm{Fe}_{\mathrm{x}} \mathrm{Sr}_{1-\mathrm{x}} \mathrm{TiO}_{3}\right.$, where $\mathrm{x}=$ the stoichiometric ratio of $\mathrm{Fe}$ precursor and $\mathrm{Sr}$ precursor controlled in preparation step) photocatalyst using the hydrothermal method followed by calcination [47]. The $\mathrm{Fe}_{0.1} \mathrm{Sr}_{0.9} \mathrm{TiO}_{3}$ sample exhibited the best $\mathrm{NH}_{3}$ production rate of $30.1 \mu \mathrm{mol} \cdot \mathrm{g}^{-1} \cdot \mathrm{h}^{-1}$, which is 3.2 times higher than that of pristine $\mathrm{SrTiO}_{3}$. By replacement of the $\mathrm{Fe}^{3+}$ ion, which has a smaller size, on the $\mathrm{Sr}^{2+}$ site in $\mathrm{SrTiO}_{3}$, the size of particles is reduced along with the corresponding increase in the surface area. Furthermore, the $\mathrm{Fe}_{0.1} \mathrm{Sr}_{0.9} \mathrm{TiO}_{3}$ photocatalyst exhibits significantly enhanced $\mathrm{N}_{2}$ chemisorption and activation ability, which Fe dopants are the major contributor to.

Vacancies Vacancy, one of defect formation strategies, leads to changes in the band structure and chemical adsorption nature on the surface [48]. This section gives an overview of intentionally induced anion vacancies in semiconductor photocatalysts and discusses how they affected the photocatalytic $\mathrm{NH}_{3}$ production.

Zhong Jin and coworkers compared the $\mathrm{NH}_{3}$ production activities using $\mathrm{BiOBr}$ semiconductors in the presence $(\mathrm{Vo}-\mathrm{BiOBr})$ or absence $(\mathrm{BiOBr})$ of oxygen vacancies [49]. The $\mathrm{Vo}-\mathrm{BiOBr}$ samples were prepared using the hydrothermal method with the addition of polyvinylpyrrolidone surfactants leading to in-situ generation of abundant vacancies, whereas pristine $\mathrm{BiO}$ Brs were synthesized without adding the surfactants. The Vo-BiOBr photocatalysts produced $\mathrm{NH}_{3}$ at a rate of $54.70 \mu \mathrm{mol} \cdot \mathrm{g}^{-1} \cdot \mathrm{h}^{-1}$ under UV-Vis irradiation, which is 10 times higher than the production rate using $\mathrm{BiOBr}$. The major contribution of this significant improvement is enhanced $\mathrm{N}_{2}$ adsorption that initiates the intermediate formation for $\mathrm{NH}_{3}$ production. For example, the amount of adsorbed $\mathrm{N}_{2}$, estimated based on $\mathrm{N}_{2}$ adsorption isotherms, on $\mathrm{Vo}-\mathrm{BiOBr}$ is considerably higher than that using $\mathrm{BiOBr}$ as shown in Fig. 4a. Furthermore, by introduction of the oxygen vacancies, the bandgap energy is reduced with the shifts in the CBM and VBM positions, which leads to increased light absorption as shown in Fig. 4b.

Chuanyi Wang and coworkers prepared metal-free g- $\mathrm{C}_{3} \mathrm{~N}_{4}$ semiconductors by thermal decomposition of melamine and induced nitrogen vacancies $\left(\mathrm{V}-\mathrm{g}-\mathrm{C}_{3} \mathrm{~N}_{4}\right)$ within the semiconductors by additional calcination under a $\mathrm{N}_{2}$ atmosphere [50]. The $\mathrm{V}-\mathrm{g}-\mathrm{C}_{3} \mathrm{~N}_{4}$ samples produced $\mathrm{NH}_{3}$ at a rate of $1240 \mu \mathrm{mol} \cdot \mathrm{g}^{-1} \mathrm{~h}^{-1}$ using pure $\mathrm{N}_{2}$ and water under visible light irradiation, whereas pristine g- $\mathrm{C}_{3} \mathrm{~N}_{4}$ produced negligible amounts of $\mathrm{NH}_{3}$. Further, morphologies and bandgap energies were not significantly varied depending on the intentional creation of $\mathrm{N}$ vacancies; however, two factors changed considerably. Due to the presence of $\mathrm{N}$ vacancies on the semiconductor, the signal collected using photoluminescence spectra decreased, indicating the reduction in the carrier recombination and enhancement of their separation. Furthermore, the $\mathrm{N}$ vacancies enable selective adsorption and activate $\mathrm{N}_{2}$, and it was experimentally confirmed that negligible amount of $\mathrm{NH}_{3}$ produced on $\mathrm{g}-\mathrm{C}_{3} \mathrm{~N}_{4}$ selectively blocked the vacancies using $\mathrm{Pd}$ particles.

\subsubsection{Coupling with multi-light absorbers}

Coupling with multi-light absorbers to form heterojunctions has been widely investigated to improve light absorption capacity under single illumination and separation of photoexcited electron-hole carriers through their designed band alignments. This strategy for catalyst design is effective in improving the photocatalytic $\mathrm{NH}_{3}$ production.

Zhong Jin and coworkers prepared $\mathrm{Bi}_{2} \mathrm{MoO}_{6} / \mathrm{Ov}$ $\mathrm{BiOBr}$ composites, where $\mathrm{Ov}$ denotes the oxygen vacancies using two-step methods, and synthesized $\mathrm{Bi}_{2} \mathrm{MoO}_{6}$ by solution-phase reflux process followed by the hydrothermal process to couple $\mathrm{Ov}-\mathrm{BiOBr}$ on as-prepared $\mathrm{Bi}_{2} \mathrm{MoO}_{6}$ [51]. Despite minimal difference in light absorption before and after coupling, the $\mathrm{Bi}_{2} \mathrm{MoO}_{6} / \mathrm{Ov}$ $\mathrm{BiOBr}$ composites showed a significantly enhanced $\mathrm{NH}_{3}$ 

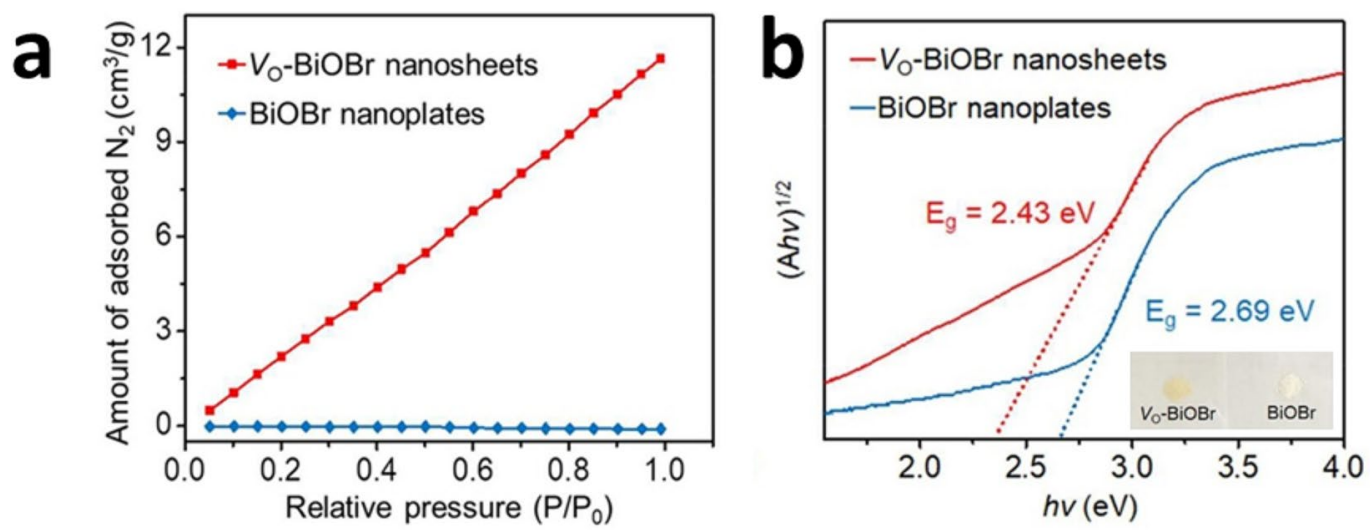

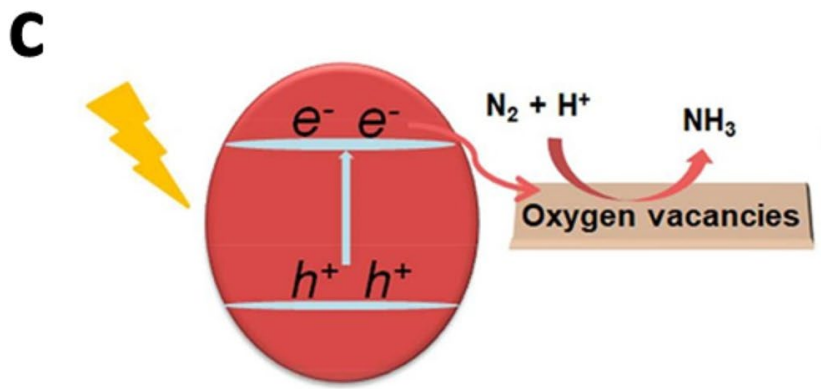

$V_{0}-\mathrm{BiOBr}$ nanosheets

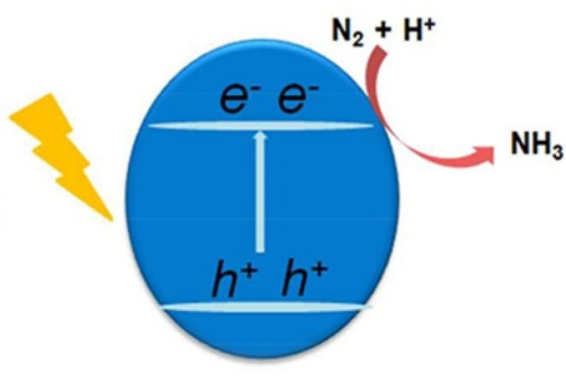

$\mathrm{BiOBr}$ nanoplates

Fig. 4 a The $\mathrm{N}_{2}$ adsorption isotherms, $\mathbf{b}$ The Tauc plot $(a h v)^{2}$ versus $(h v)$ and $\mathbf{c}$ The schematic illustration of pohtocatalytic $\mathrm{NH}_{3}$ synthesis process on Vo-BiOBr nanosheets and BiOBr nanoplates, respectively. Reproduced with permission [49]. Copyright 2018, American Chemical Society

production rate $\left(90.7 \mu \mathrm{mol} \cdot \mathrm{g}^{-1} \mathrm{~h}^{-1}\right)$, which is almost 30 and 3 times higher than the rates evaluated using $\mathrm{Bi}_{2} \mathrm{MoO}_{6}$ and $\mathrm{Ov}-\mathrm{BiOBr}$, respectively as shown in Fig. $5 \mathrm{a}$. The major role of coupling is the formation of cascaded band alignments at the interface between two semiconductors. The photoexcited holes are transported and oxidize the electron donor on $\mathrm{Bi}_{2} \mathrm{MoO}_{6}$ where the $\mathrm{VBM}$ is located relatively higher, whereas the photoexcited electrons are transported and reduce $\mathrm{N}_{2}$ on $\mathrm{Ov}-\mathrm{BiOBr}$ where the CBM located relatively lower. Furthermore, oxygen vacancies on $\mathrm{BiOBr}$ show synergistic effects on the $\mathrm{NH}_{3}$ production by providing $\mathrm{N}_{2}$ adsorption and activation sites as shown in Fig. 5b.

Jimmy $\mathrm{Yu}$ and coworkers prepared $\mathrm{Ov}-\mathrm{TiO}_{2}$ using the hydrothermal method followed by loading Au nanoparticles. The Au nanoparticles generate hot electrons under visible light illumination [51], which is known as plasmonic phenomena. The hot electrons are injected into the $\mathrm{CBM}$ of $\mathrm{TiO}_{2}$ and then trapped in vacant sites where $\mathrm{N}_{2}$ is reduced into $\mathrm{NH}_{3}$. The generated holes remain on $\mathrm{Au}$ and oxidize the electron donors, methanol, in solution as shown in Fig. $5 \mathrm{c}$ and d. The optimized $\mathrm{Au} / \mathrm{TiO}_{2}-\mathrm{Ov}$ samples produced $\mathrm{NH}_{3}$ with a rate of $78.6 \mu \mathrm{mol} \cdot \mathrm{g}^{-1} \cdot \mathrm{h}^{-1}$ under visible light irradiation, which is at least 98 and 35 times higher those using $\mathrm{Au} / \mathrm{TiO}_{2}$ and $\mathrm{TiO}_{2}$-Ov photocatalysts, respectively.

\subsubsection{Surface modification and reaction engineering}

As discussed above, photocatalytic activities have been developed significantly by modifying photocatalysts, for example, defects engineering and composite formation. However, although photogenerated charge generation and separation are advanced by multiple possible strategies, if the surfaces of the semiconductors exhibit slow charge injection and are poorly catalytic for $\mathrm{N}_{2}$ reduction, the $\mathrm{NH}_{3}$ production rate may not be enhanced directly. The surface modification on the semiconductors using a robust electrocatalyst (cocatalyst) for $\mathrm{N}_{2}$ to $\mathrm{NH}_{3}$ conversion is the simplest way to improve the limiting factor at the interface between the semiconductors and liquid where reactants are present. Therefore, the modification of the semiconductor surface with various $\mathrm{NH}_{3}$ production catalysts, such as $\mathrm{Ru}, \mathrm{Cu}$, and $\mathrm{Au}$, has been investigated $[20,34,53]$. 

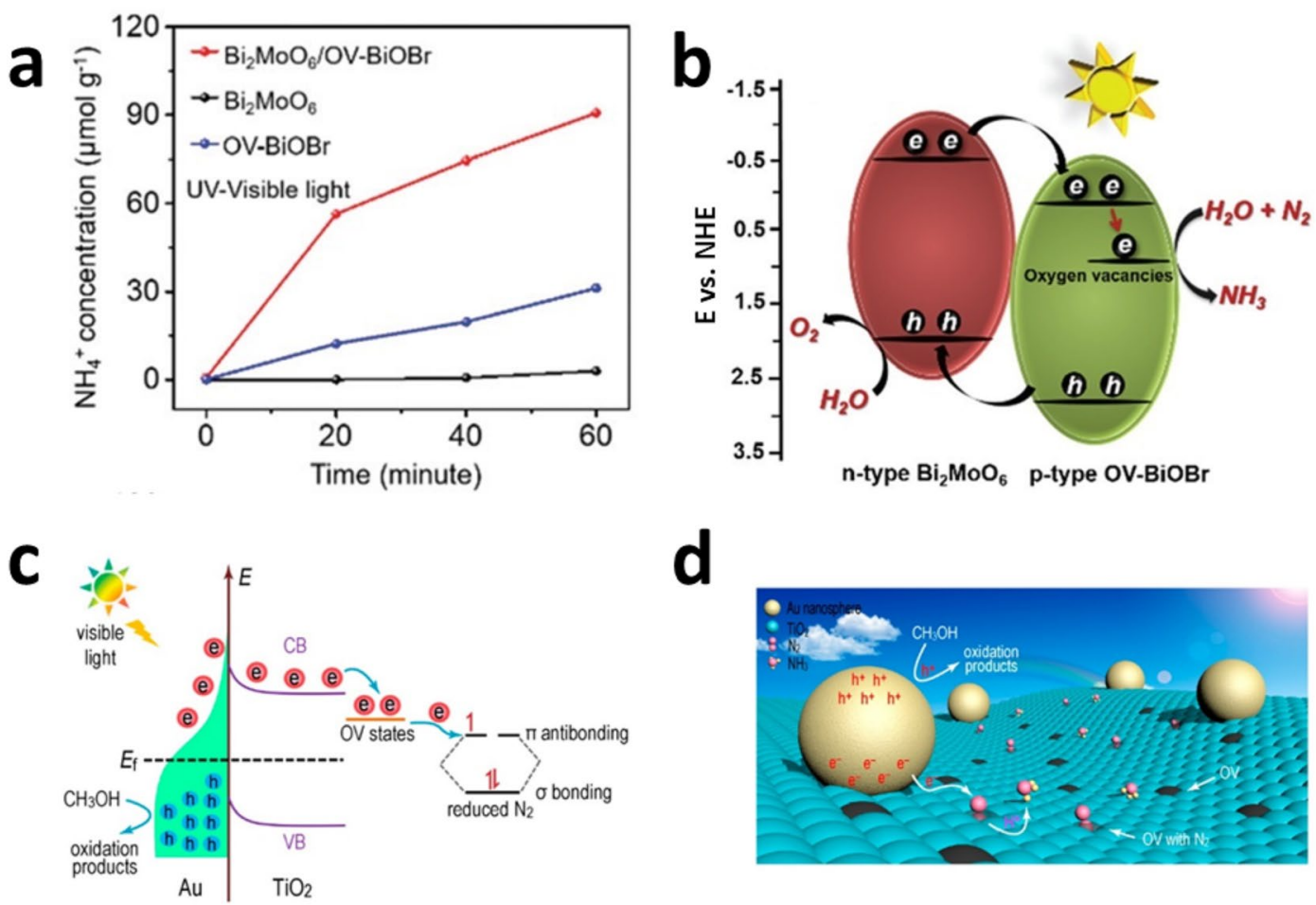

Fig. 5 a NH${ }_{4}{ }^{+}$concentrations of $\mathrm{Bi}_{2} \mathrm{MoO}_{6} / \mathrm{Ov}$ - $\mathrm{BiOBr}$ heterojunctions, $\mathrm{Bi}_{2} \mathrm{MoO}_{6}$ and $\mathrm{BiOBr}$ alone, respectively. $\mathbf{b}$ The scheme of proposed $\mathrm{Bi}_{2} \mathrm{MoO}_{6} /$ $\mathrm{BiOBr}$ heterojunctions. Reproduced with permission [51]. Copyright 2019, The Royal Society of Chemistry. c The schematic reaction mechanism and d the artistic illustration of $\mathrm{Au} / \mathrm{TiO}_{2}$-Ov photocatalyst. Reproduced with permission [52]. Copyright 2018, American Chemical Society

In contrast, since the rates of reduction and oxidation reactions always correspond to one another, the sluggish photo-oxidation using holes may become a limiting factor for the photocatalytic $\mathrm{NH}_{3}$ production. To overcome the possible limitation, it has been widely suggested to load appropriate electrocatalysts (cocatalysts) for water oxidation on the semiconductor or provide a more facile hole acceptor (electron donors) than water, such as methanol or ethanol (Table 1).

\section{Summary and outlook}

In summary, we reviewed the mechanistic and experimental steps for photocatalytic $\mathrm{NH}_{3}$ production and examined various strategies to modify photocatalysts employed to enhance the production activities. This review clearly shows that although significant development of photocatalyts has been reported thus far, further advances for practical $\mathrm{NH}_{3}$ production are required. First, the efficiency for charge generation via solar light absorption should be enhanced. Considering that the majority of incident photons are in the range of visible light, development of absorbers, can harvest the incident solar light, is required by determining appropriate materials and engineering semiconductors.
The charge separation effect is also required for photocatalytic $\mathrm{NH}_{3}$ production through suppression of their recombination. For example, strategies for doping and composite formation will exhibit advances in the future and may increase the photon absorption efficiency simultaneously. In addition, morphology engineering [72-76] for photocatalysts will be promising and can be achieved by controlling the distances for carrier transportation and lifetime duration between the photo-induced generation and recombination. Furthermore, this may change facets and surface area, thereby providing active sites for the redox reactions using transported carriers. Moreover, if the facets are optimized with increasing surface area, morphology engineering can be significantly beneficial for $\mathrm{NH}_{3}$ production.

With improvements in photon absorption and charge separation, surface engineering will be able to provide active sites where $\mathrm{N}_{2}$ reduction using electrons and oxidation using holes is important. Thus, defect engineering, for example, formation of vacancies, cocatalyst coupling, and applying sacrificial reagents have been suggested. It is noteworthy that $\mathrm{N}_{2}$ diffusivity control close to photocatalysts make an important contribution to practical photocatalytic $\mathrm{NH}_{3}$ production. For instance, 
Table 1 The summary of photocatalytic nitrogen reduction performances and its operating conditions: photocatalysts

\begin{tabular}{|c|c|c|c|c|c|}
\hline Photocatalysts & Light source & Hole scavenger & Ammonia production rate & Ammonia detection methods & Refs \\
\hline $\mathrm{PCN} / \mathrm{rGO}(0.2)$ & $\begin{array}{r}250 \text { W Xe lamp } 400 \\
\mathrm{~nm}<\lambda<800 \mathrm{~nm}\end{array}$ & $1 \mathrm{mM}$ EDTA-2Na & $544.6 \mu \mathrm{mol} \cdot \mathrm{L}^{-1} \cdot \mathrm{g}^{-1} \cdot \mathrm{h}^{-1}$ & Nessler's reagent ${ }^{b}$ & [14] \\
\hline $\mathrm{Ru} / \mathrm{TiO}_{2}$ & 300 W Xe lamp & $20 \% \mathrm{C}_{2} \mathrm{H}_{5} \mathrm{OH}$ & $3.31 \mu \mathrm{mol} \cdot \mathrm{g}^{-1} \cdot \mathrm{h}^{-1}$ & Indophenol blue & {$[20]$} \\
\hline $\mathrm{Cu} / \mathrm{g}-\mathrm{C}_{3} \mathrm{~N}_{4}$ & $\begin{array}{l}300 \text { W Xe lamp } 400 \mathrm{~nm}<\lambda<800 \\
\mathrm{~nm}\end{array}$ & $20 \% \mathrm{C}_{2} \mathrm{H}_{5} \mathrm{OH}$ & $186 \mu \mathrm{mol} \cdot \mathrm{g}^{-1} \cdot \mathrm{h}^{-1}$ & Nessler's reagent & [34] \\
\hline $\mathrm{Ni}-0.8-\mathrm{TiO}_{2}$ & 300 W Xe lamp & None & $46.80 \mu \mathrm{mol} \cdot \mathrm{g}^{-1} \cdot \mathrm{h}^{-1}$ & Nessler's reagent & {$[45]$} \\
\hline $6 \%-\mathrm{TiO}_{2}$ & 300 W Xe lamp & None & $78.9 \mu \mathrm{mol} \cdot \mathrm{g}^{-1} \cdot \mathrm{h}^{-1}$ & Nessler's reagent & {$[46]$} \\
\hline $\mathrm{Fe}_{0.1} \mathrm{Sr}_{0.9} \mathrm{TiO}_{3}$ & 300 W Xe lamp & None & $30.1 \mu \mathrm{mol} \cdot \mathrm{g}^{-1} \cdot \mathrm{h}^{-1}$ & Nessler's reagent & [47] \\
\hline Vo-BiOBr nanosheets & 300 W Xe lamp & None & $54.70 \mu \mathrm{mol} \cdot \mathrm{g}^{-1} \cdot \mathrm{h}^{-1}$ & Nessler's reagent & [49] \\
\hline$V-g-C_{3} N_{4}^{a}$ & 300 W Xe lamp $420 \mathrm{~nm}>\lambda$ & $20 \% \mathrm{CH}_{3} \mathrm{OH}$ & $1240 \mu \mathrm{mol} \cdot \mathrm{g}^{-1} \cdot \mathrm{h}^{-1}$ & Nessler's reagent & {$[50]$} \\
\hline $\mathrm{Bi}_{2} \mathrm{MoO}_{6} / \mathrm{Ov}-\mathrm{BiOBr}$ & 300 W Xe lamp & None & $90.7 \mu \mathrm{mol} \cdot \mathrm{g}^{-1} \cdot \mathrm{h}^{-1}$ & Nessler's reagent & [51] \\
\hline $\mathrm{Au} / \mathrm{TiO}_{2}-\mathrm{Ov}$ & $300 W$ Xe lamp $420 \mathrm{~nm}>\lambda$ & $10 \% \mathrm{CH}_{3} \mathrm{OH}$ & $78.6 \mu \mathrm{mol} \cdot \mathrm{g}^{-1} \cdot \mathrm{h}^{-1}$ & Indophenol blue & {$[52]$} \\
\hline $\mathrm{Au} /(\mathrm{BiO})_{2} \mathrm{CO}_{3}$ & 300 W Xe lamp & None & $38.2 \mu \mathrm{mol} \cdot \mathrm{g}^{-1} \cdot \mathrm{h}^{-1}$ & Indophenol blue & [53] \\
\hline $\mathrm{BiOCl}$ & 500 W Xe lamp & $25 \% \mathrm{CH}_{3} \mathrm{OH}$ & $92.4 \mu \mathrm{mol} \cdot \mathrm{g}^{-1} \cdot \mathrm{h}^{-1}$ & Nessler's reagent & [54] \\
\hline $\mathrm{Bi}_{5} \mathrm{O}_{7} \mathrm{I}$ & 300 W Xe lamp & $20 \% \mathrm{CH}_{3} \mathrm{OH}$ & $111.5 \mu \mathrm{mol} \cdot \mathrm{L}^{-1} \cdot \mathrm{h}^{-1}$ & Nessler's reagent & {$[55]$} \\
\hline $\mathrm{Bi}_{5} \mathrm{O}_{7} \mathrm{Br}$ & 300 W Xe lamp $400 \mathrm{~nm}>\lambda$ & None & $1380 \mu \mathrm{mol} \cdot \mathrm{g}^{-1} \cdot \mathrm{h}^{-1}$ & Nessler's reagent & {$[56]$} \\
\hline 20Fe-2Al@3DGraphene & 500 W Hg lamp & None & $430 \mu \mathrm{mol} \cdot \mathrm{g}^{-1} \cdot \mathrm{h}^{-1}$ & Indophenol blue & {$[57]$} \\
\hline Ultrathin $\mathrm{MoS}_{2}$ & 500 W Xe lamp $420 \mathrm{~nm}>\lambda$ & None & $325 \mu \mathrm{mol} \cdot \mathrm{g}^{-1} \cdot \mathrm{h}^{-1}$ & Isotopic labeling & {$[58]$} \\
\hline CuCr-NSs & 300 W Xe lamp $400 \mathrm{~nm}>\lambda$ & None & $184.8 \mu \mathrm{mol} \cdot \mathrm{L}^{-1} \cdot \mathrm{h}^{-1}$ & Nessler's reagent & [59] \\
\hline Mo-doped $\mathrm{W}_{18} \mathrm{O}_{49}$ & 300 W Xe lamp & $1 \mathrm{mM} \mathrm{Na}_{2} \mathrm{SO}_{3}$ & $195.5 \mu \mathrm{mol} \cdot \mathrm{g}^{-1} \cdot \mathrm{h}^{-1}$ & $\begin{array}{l}\text { Nessler's reagent, lon chroma- } \\
\text { tography }\end{array}$ & {$[60]$} \\
\hline $\mathrm{BiO}$ quantum dots & 500 W Xe lamp & None & $1226 \mu \mathrm{mol} \cdot \mathrm{g}^{-1} \cdot \mathrm{h}^{-1}$ & Indophenol blue & [61] \\
\hline $\mathrm{C}-\mathrm{WO}_{3} \cdot \mathrm{H}_{2} \mathrm{O}$ & 500 W Xe lamp & None & $205 \mu \mathrm{mol} \cdot \mathrm{g}^{-1} \cdot \mathrm{h}^{-1}$ & Nessler's reagent & [62] \\
\hline Fe-doped g- $\mathrm{C}_{3} \mathrm{~N}_{4}$ & $\begin{array}{c}250 \mathrm{~W} \text { Na lamp } 400 \\
\mathrm{~nm}<\lambda<800 \mathrm{~nm}\end{array}$ & $0.1 \% \mathrm{C}_{2} \mathrm{H}_{5} \mathrm{OH}$ & $317.1 \mu \mathrm{mol} \cdot \mathrm{L}^{-1} \cdot \mathrm{g}^{-1} \cdot \mathrm{h}^{-1}$ & Nessler's reagent & [63] \\
\hline 5\%Ru@n-GaN NWs & 300 W Xe lamp & None & $120 \mu \mathrm{mol} \cdot \mathrm{g}^{-1} \cdot \mathrm{h}^{-1}$ & Indophenol blue & {$[64]$} \\
\hline $\mathrm{Ga}_{2} \mathrm{O}_{3}-\mathrm{DBD} / \mathrm{g}-\mathrm{C}_{3} \mathrm{~N}_{4}$ & 500 W Xe lamp & $0.04 \mathrm{mMCH}_{3} \mathrm{OH}$ & $112.5 \mu \mathrm{mol} \cdot \mathrm{L}^{-1} \cdot \mathrm{h}^{-1}$ & Nessler's reagent & [65] \\
\hline $\mathrm{TiO}_{2} @ \mathrm{C} / \mathrm{g}-\mathrm{C}_{3} \mathrm{~N}_{4}$ & 300 W Xe lamp $420 \mathrm{~nm}>\lambda$ & $20 \% \mathrm{CH}_{3} \mathrm{OH}$ & $250.6 \mu \mathrm{mol} \cdot \mathrm{g}^{-1} \cdot \mathrm{h}^{-1}$ & Nessler's reagent & {$[66]$} \\
\hline $\mathrm{g}-\mathrm{C}_{3} \mathrm{~N}_{4} / \mathrm{MgAlFeO}$ & $\begin{array}{c}250 \mathrm{~W} \text { Na lamp } 400 \\
\mathrm{~nm}<\lambda<800 \mathrm{~nm}\end{array}$ & $0.1 \% \mathrm{C}_{2} \mathrm{H}_{5} \mathrm{OH}$ & $440.4 \mu \mathrm{mol} \cdot \mathrm{L}^{-1} \cdot \mathrm{g}^{-1} \cdot \mathrm{h}^{-1}$ & Nessler's reagent & [67] \\
\hline $\mathrm{TiO}_{2} / \mathrm{Au} / \mathrm{a}-\mathrm{TiO}_{2}$ & 300 W Xe lamp & None & $0.0134 \mu \mathrm{mol} \cdot \mathrm{cm}^{-2} \cdot \mathrm{h}^{-1}$ & Indophenol blue & {$[68]$} \\
\hline $\mathrm{Fe}_{2} \mathrm{O}_{3}$ & 500 W Xe lamp & $0.1 \% \mathrm{C}_{2} \mathrm{H}_{5} \mathrm{OH}$ & $1362.5 \mu \mathrm{mol} \cdot \mathrm{L}^{-1} \cdot \mathrm{h}^{-1}$ & Nessler's reagent & [69] \\
\hline $\mathrm{H}-\mathrm{Bi}_{2} \mathrm{MoO}_{6}$ & $\begin{array}{l}300 \text { W Xe lamp with a } 420 \text { nm cutoff } \\
\text { filter }\end{array}$ & None & $1300 \mu \mathrm{mol} \cdot \mathrm{g}^{-1} \cdot \mathrm{h}^{-1}$ & Nessler's reagent & [70] \\
\hline
\end{tabular}

${ }^{\text {a }}$ Where $\mathrm{V}$ denoted nitrogen vacancies

${ }^{\mathrm{b}}$ Nessler's reagent, $\mathrm{K}_{2} \mathrm{Hgl}_{4}$, is one of photometric indicators for $\mathrm{NH}_{3}$ detection and quantification [71]

importance of three-phase interfaces, where a catalyst and two phases reactants such as water and active gas faced, has been demonstrated [7778]. This indicates that even if highly robust catalysts are prepared, if the supply of $\mathrm{N}_{2}$ gas and water is insufficient at the region close to the catalyst, the $\mathrm{NH}_{3}$ production is limited. Thus, environmental engineering, for example, via hydrophobicity control on the catalysts, will be significantly effective. The mechanism, experimental methods, discussion, insights, and suggestions contained in this review provide a good fundamental and foundation for further improvement of photocatalytic $\mathrm{NH}_{3}$ production.

\section{Acknowledgements}

Not applicable.

\section{Authors' contributions}

SC, SMK, YL, JS, JJ, and Prof. YJJ contributed to prepare this review. Prof. YJJ and Prof. JSL supervised this work and Prof. YJJ, Prof. JSL and SC are major contributors in writing the manuscript. All authors read and approved the final manuscript.

\section{Funding}

This work was supported by the research fund of Hanyang University (HY202000000002708), the Korea Institute of Energy Technology Evaluation and Planning (KETEP) and the Ministry of Trade, Industry \& Energy(MOTIE) (No. 20202020800330), the Graduate school of Post Plastic specialization of Korea Environmental Industry \& Technology Institute grant funded by the Ministry of Environment of Republic of Korea and National Research Foundation 
(NRF) Grant funded by the Korea government (No. 2020R1G1A1100104, No. 2019M1A2A2065612, No. 2018R1A2A1A05077909).

\section{Availability of data and materials}

The datasets used and analysed during the current study are available from the corresponding references listed.

\section{Declarations}

\section{Competing interests}

The authors declare that they have no competing interests.

Received: 30 May 2021 Accepted: 12 July 2021

Published online: 02 August 2021

\section{References}

1. J.W. Erisman, M.A. Sutton, J. Galloway, Z. Klimont, W. Winiwarter, How a century of ammonia synthesis changed the world. Nat. Geosci. 1(10), 636 (2008)

2. V. Smil, Detonator of the population explosion. Nature $\mathbf{4 0 0}(6743), 415$ (1999)

3. J.G. Chen, R.M. Crooks, L.C. Seefeldt et al., Beyond fossil fuel-driven nitrogen transformations. Science $\mathbf{3 6 0}$ (6391), eaar6611 (2018)

4. Y.J. Jang, K.S. Choi, Enabling electrochemical $\mathrm{N}_{2}$ reduction to $\mathrm{NH}_{3}$ in the low overpotential region using non-noble metal Bi electrodes via surface composition modification. J Mater Chem A 8(27), 13842 (2020)

5. D.R. MacFarlane, P.V. Cherepanov, J. Choi, B.H.R. Suryanto, R.Y. Hodgetts, J.M. Bakker, F.M.F. Vallana, A.N. Simonov, A roadmap to the ammonia economy. Joule 4(6), 1186 (2020)

6. J. John, D.K. Lee, U. Sim, Photocatalytic and electrocatalytic approaches towards atmospheric nitrogen reduction to ammonia under ambient conditions. Nano Converg. 6(1), 15 (2019)

7. K. Ithisuphalap, H. Zhang, L. Guo, Q. Yang, H. Yang, G. Wu, Photocatalysis and photoelectrocatalysis methods of nitrogen reduction for sustainable ammonia synthesis. Small Methods 3(6), 1800352 (2019)

8. Y.J. Jang, A.E. Lindberg, M.A. Lumley, K.S. Choi, Photoelectrochemical nitrogen reduction to ammonia on cupric and cuprous oxide photocathodes. ACS Energy Lett. 5(6), 1834 (2020)

9. G.N. Schrauzer, T.D. Guth, Photolysis of water and photoreduction of nitrogen on titanium dioxide. J Am Chem. Soc. 99(22), 7189 (1977)

10. G. Zhang, X. Yang, C. He, P. Zhang, H. Mi, Constructing a tunable defect structure in $\mathrm{TiO}_{2}$ for photocatalytic nitrogen fixation. J. Mater. Chem. A 8(1), 334 (2020)

11. E. Endoh, J.K. Leland, A.J. Bard, Heterogeneous photoreduction of nitrogen to ammonia on tungsten oxide. J. Phys. Chem 90(23), 6223 (1986)

12. Q.S. Li, K. Domen, S. Naito, T. Onishi, K. Tamaru, Photocatalytic synthesis and photodecomposition of ammonia over $\mathrm{SrTiO}_{3}$ and $\mathrm{BaTiO}_{3}$ based catalysts. Chem. Lett. 12(3), 321 (1983)

13. Y. Zhao, S. Zhou, J. Zhao, Y. Du, S.X. Dou, Control of photocarrier separation and recombination at bismuth oxyhalide interface for nitrogen fixation. J. Phys. Chem. Lett. 11(21), 9304 (2020)

14. L. Yu, Z. Mo, X. Zhu, J. Deng, F. Xu, Y. Song, Y. She, H. Li, and H. Xu, Construction of 2D/2D Z-scheme $\mathrm{MnO}_{2-x} / \mathrm{g}-\mathrm{C}_{3} \mathrm{~N}_{4}$ photocatalyst for efficient nitrogen fixation to ammonia, Green Energy Environ., (2020)

15. H. Gal, G. Alan, F. Frank A. et al., The potential economic feasibility of direct electrochemical nitrogen reduction as a route to ammonia, ChemRxiv, (2019)

16. M. Pourbaix, Atlas of electrochemical equilibria in aqueous solutions (National Association of Corrosion Engineers, Houston, Tex., 1974).

17. L. Zhang, H.H. Mohamed, R. Dillert, D. Bahnemann, Kinetics and mechanisms of charge transfer processes in photocatalytic systems: a review. J. Photochem. Photobiol. C-Photochem. Rev. 13(4), 263 (2012)

18. M.A. Lumley, A. Radmilovic, Y.J. Jang, A.E. Lindberg, K.S. Choi, Perspectives on the development of oxide-based photocathodes for solar fuel production. J. Am. Chem. Soc. 141(46), 18358 (2019)

19. W. Zhao, J. Zhang, X. Zhu, M. Zhang, J. Tang, M. Tan, Y. Wang, Enhanced nitrogen photofixation on Fe-doped $\mathrm{TiO}_{2}$ with highly exposed (101) facets in the presence of ethanol as scavenger. Appl. Catal. B-Environ. 144, $468(2014)$

20. S. Liu, Y. Wang, S. Wang et al., Photocatalytic fixation of nitrogen to ammonia by single $\mathrm{Ru}$ atom decorated $\mathrm{TiO}_{2}$ nanosheets. ACS Sustain. Chem. Eng. 7(7), 6813 (2019)

21. Z. Yan, H. Wu, A. Han, X. Yu, P. Du, Noble metal-free cobalt oxide $\left(\mathrm{CoO}_{x}\right)$ nanoparticles loaded on titanium dioxide/cadmium sulfide composite for enhanced photocatalytic hydrogen production from water. Int. J. Hydrog. Energy 39(25), 13353 (2014)

22. X. Yue, S. Yi, R. Wang, Z. Zhang, S. Qiu, Cobalt phosphide modified titanium oxide nanophotocatalysts with significantly enhanced photocatalytic hydrogen evolution from water splitting. Small 13(14), 1603301 (2017)

23. S. Chen, D. Liu, T. Peng, Fundamentals and recent progress of photocatalytic nitrogen-fixation reaction over semiconductors. Sol. RRL 5(2), 2000487 (2021)

24. S. Zhang, Y. Zhao, R. Shi, G.I.N. Waterhouse, T. Zhang, Photocatalytic ammonia synthesis: recent progress and future. EnergyChem 1(2), 100013 (2019)

25. P. Chen, N. Zhang, S. Wang et al., Interfacial engineering of cobalt sulfide/ graphene hybrids for highly efficient ammonia electrosynthesis. Proc. Natl. Acad. Sci. U. S. A.116(14), 6635 (2019)

26. Y. Zhao, R. Shi, X. Bian et al., Ammonia detection methods in photocataIytic and electrocatalytic experiments: how to improve the reliability of $\mathrm{NH}_{3}$ production rates? Adv. Sci. 6(8), 1802109 (2019)

27. M. Cong, X. Chen, K. Xia, X. Ding, L. Zhang, Y. Jin, Y. Gao, L. Zhang, Selective nitrogen reduction to ammonia on iron porphyrin-based single-site metal-organic frameworks. J. Mater. Chem. A 9(8), 4673 (2021)

28. S.Z. Andersen, V. Čolić, S. Yang et al., A rigorous electrochemical ammonia synthesis protocol with quantitative isotope measurements. Nature 570(7762), 504 (2019)

29. L. Li, C. Tang, D. Yao, Y. Zheng, S.Z. Qiao, Electrochemical nitrogen reduction: identification and elimination of contamination in electrolyte. ACS Energy Lett. 4(9), 2111 (2019)

30. A.C. Nielander, J.M. McEnaney, J.A. Schwalbe et al., A versatile method for ammonia detection in a range of relevant electrolytes via direct nuclear magnetic resonance techniques. ACS Catal. 9(7), 5797 (2019)

31. F. Wu, Y. Yu, H. Yang et al., Simultaneous enhancement of charge separation and hole transportation in $\mathrm{T} \mathrm{TiO}_{2}-\mathrm{SrTiO}_{3}$ core-shell nanowire photoelectrochemical system. Adv. Mater. 29(28), 1701432 (2017)

32. B. Huang, Y. Liu, Q. Pang, X. Zhang, H. Wang, P.K. Shen, Boosting the photocatalytic activity of mesoporous $\mathrm{SrTiO}_{3}$ for nitrogen fixation through multiple defects and strain engineering. J. Mater. Chem. A 8(42), 22251 (2020)

33. Z. Ying, S. Chen, S. Zhang, T. Peng, R. Li, Efficiently enhanced $\mathrm{N}_{2}$ photofixation performance of sea-urchin-like $\mathrm{W}_{18} \mathrm{O}_{49}$ microspheres with $\mathrm{Mn}$ doping. Appl. Catal. B-Environ. 254, 351 (2019)

34. P. Huang, W. Liu, Z. He et al., Single atom accelerates ammonia photosynthesis. Sci. China-Chem. 61(9), 1187 (2018)

35. S. Hu, X. Chen, Q. Li, Y. Zhao, W. Mao, Effect of sulfur vacancies on the nitrogen photofixation performance of ternary metal sulfide photocatalysts. Catal. Sci. Technol. 6(15), 5884 (2016)

36. D.S. Bhachu, S.J.A. Moniz, S. Sathasivam et al., Bismuth oxyhalides: synthesis, structure and photoelectrochemical activity. Chem. Sci. 7(8), 4832 (2016)

37. J. Li, H. Li, G. Zhan, L. Zhang, Solar water splitting and nitrogen fixation with layered bismuth oxyhalides. Accounts Chem. Res. 50(1), 112 (2017)

38. W.L. Huang, Electronic structures and optical properties of $\mathrm{BiOX}(\mathrm{X}=\mathrm{F}, \mathrm{Cl}$, $\mathrm{Br}$, I) via DFT calculations. J. Comput. Chem. 30(12), 1882 (2009)

39. S. Liu, S. Wang, Y. Jiang, Z. Zhao, G. Jiang, Z. Sun, Synthesis of $\mathrm{Fe}_{2} \mathrm{O}_{3}$ loaded porous $\mathrm{g}-\mathrm{C}_{3} \mathrm{~N}_{4}$ photocatalyst for photocatalytic reduction of dinitrogen to ammonia. Chem. Eng. J. 373, 572 (2019)

40. R. Liu, Z. Chen, Y. Yao, Y. Li, W.A. Cheema, D. Wang, S. Zhu, Recent advancements in $\mathrm{g}-\mathrm{C}_{3} \mathrm{~N}_{4}$-based photocatalysts for photocatalytic $\mathrm{CO}_{2}$ reduction: a mini review. RSC Adv. 10(49), 29408 (2020)

41. R. Shi, Y. Zhao, G.I.N. Waterhouse, S. Zhang, T. Zhang, Defect engineering in photocatalytic nitrogen fixation. ACS Catal. 9(11), 9739 (2019)

42. Y.J. Jang, M.D. Bhatt, J. Lee, S.H. Choi, B.J. Lee, J.S. Lee, Metal-free artificial photosynthesis of carbon monoxide using $\mathrm{N}$-doped ZnTe nanorod photocathode decorated with $\mathrm{N}$-doped carbon electrocatalyst layer. Adv. Energy Mater. 8(20), 1702636 (2018) 
43. J.H. Kim, Y.J. Jang, S.H. Choi, B.J. Lee, J.H. Kim, Y.B. Park, C.M. Nam, H.G. $\mathrm{Kim}$, J.S. Lee, A multitude of modifications strategy of $\mathrm{ZnFe}_{2} \mathrm{O}_{4}$ nanorod photoanodes for enhanced photoelectrochemical water splitting activity. J. Mater. Chem. A 6(26), 12693 (2018)

44. Y.J. Jang, Y.B. Park, H.E. Kim, Y.H. Choi, S.H. Choi, J.S. Lee, Oxygen-intercalated $\mathrm{CuFeO}_{2}$ photocathode fabricated by hybrid microwave annealing for efficient solar hydrogen production. Chem. Mat. 28(17), 6054 (2016)

45. J. Li, D. Wang, R. Guan, Y. Zhang, Z. Zhao, H. Zhai, Z. Sun, Vacancy-enabled mesoporous $\mathrm{TiO}_{2}$ modulated by nickel doping with enhanced photocatalytic nitrogen fixation performance. ACS Sustain. Chem. Eng. 8(49), 18258 (2020)

46. Y. Zhao, Y. Zhao, R. Shi, B. Wang, G.I.N. Waterhouse, L.Z. Wu, C.H. Tung, T. Zhang, Tuning oxygen vacancies in ultrathin $\mathrm{TiO}_{2}$ nanosheets to boost photocatalytic nitrogen fixation up to $700 \mathrm{~nm}$. Adv. Mater. 31(16), 1806482 (2019)

47. Z. Ying, S. Chen, T. Peng, R. Li, J. Zhang, Fabrication of an Fe-doped $\mathrm{SrTiO}_{3}$ photocatalyst with enhanced dinitrogen photofixation performance. Eur. J. Inorg. Chem. 2019(16), 2182 (2019)

48. M. Li, H. Huang, J. Low, C. Gao, R. Long, Y. Xiong, Recent progress on electrocatalyst and photocatalyst design for nitrogen reduction. Small Methods 3(6), 1800388 (2019)

49. X. Xue, R. Chen, H. Chen et al., Oxygen vacancy engineering promoted photocatalytic ammonia synthesis on ultrathin two-dimensional bismuth oxybromide nanosheets. Nano Lett. 18(11), 7372 (2018)

50. G. Dong, W. Ho, C. Wang, Selective photocatalytic $\mathrm{N}_{2}$ fixation dependent on g- $\mathrm{C}_{3} \mathrm{~N}_{4}$ induced by nitrogen vacancies. J. Mater. Chem. A 3(46), 23435 (2015)

51. X. Xue, R. Chen, C. Yan, Y. Hu, W. Zhang, S. Yang, L. Ma, G. Zhu, Z. Jin, Efficient photocatalytic nitrogen fixation under ambient conditions enabled by the heterojunctions of n-type $\mathrm{Bi}_{2} \mathrm{MoO}_{6}$ and oxygen-vacancy-rich p-type BiOBr. Nanoscale 11(21), 10439 (2019)

52. J. Yang, Y. Guo, R. Jiang, F. Qin, H. Zhang, W. Lu, J. Wang, J.C. Yu, Highefficiency "working-in-tandem" nitrogen photofixation achieved by assembling plasmonic gold nanocrystals on ultrathin titania nanosheets. J. Am. Chem. Soc. 140(27), 8497 (2018)

53. C. Xiao, H. Hu, X. Zhang, D.R. MacFarlane, Nanostructured gold/bismutite hybrid heterocatalysts for plasmon-enhanced photosynthesis of ammonia. ACS Sustain. Chem. Eng. 5(11), 10858 (2017)

54. H. Li, J. Shang, J. Shi, K. Zhao, L. Zhang, Facet-dependent solar ammonia synthesis of $\mathrm{BiOCl}$ nanosheets via a proton-assisted electron transfer pathway. Nanoscale 8(4), 1986 (2016)

55. Y. Bai, L. Ye, T. Chen, L. Wang, X. Shi, X. Zhang, D. Chen, Facet-dependent photocatalytic $\mathrm{N}_{2}$ fixation of bismuth-rich $\mathrm{Bi}_{5} \mathrm{O}_{7}$ I nanosheets. ACS Appl. Mater. Interfaces 8(41), 27661 (2016)

56. S. Wang, X. Hai, X. Ding, K. Chang, Y. Xiang, X. Meng, Z. Yang, H. Chen, J. Ye, Light-switchable oxygen vacancies in ultrafine Bi5O7Br nanotubes for boosting solar-driven nitrogen fixation in pure water. Adv. Mater. 29(31), 1701774 (2017)

57. Y. Yang, T. Zhang, Z. Ge, Y. Lu, H. Chang, P. Xiao, R. Zhao, Y. Ma, Y. Chen, Highly enhanced stability and efficiency for atmospheric ammonia photocatalysis by hot electrons from a graphene composite catalyst with $\mathrm{Al}_{2} \mathrm{O}_{3}$. Carbon 124, 72 (2017)

58. S. Sun, X. Li, W. Wang, L. Zhang, X. Sun, Photocatalytic robust solar energy reduction of dinitrogen to ammonia on ultrathin $\mathrm{MoS}_{2}$. Appl. Catal. B-Environ. 200, 323 (2017)

59. Y. Zhao, Y. Zhao, G.I.N. Waterhouse et al., Layered-double-hydroxide nanosheets as efficient visible-light-driven photocatalysts for dinitrogen fixation. Adv. Mater. 29(42), 1703828 (2017)

60. N. Zhang, A. Jalil, D. Wu et al., Refining defect states in $\mathrm{W}_{18} \mathrm{O}_{49}$ by $\mathrm{Mo}$ doping: A strategy for tuning $\mathrm{N}_{2}$ activation towards solar-driven nitrogen fixation. J. Am. Chem. Soc. 140(30), 9434 (2018)

61. S. Sun, Q. An, W. Wang, L. Zhang, J. Liu, W.A.G. lii, Efficient photocatalytic reduction of dinitrogen to ammonia on bismuth monoxide quantum dots. J. Mater. Chem. A 5(1), 201 (2017)
62. X. Li, W. Wang, D. Jiang, S. Sun, L. Zhang, X. Sun, Efficient solar-driven nitrogen fixation over carbon-tungstic-acid hybrids. Chem. Eur. J. 22(39), $13819(2016)$

63. S. Hu, X. Chen, Q. Li, F. Li, Z. Fan, H. Wang, Y. Wang, B. Zheng, G. Wu, $\mathrm{Fe}^{3+}$ doping promoted $\mathrm{N}_{2}$ photofixation ability of honeycombed graphitic carbon nitride: the experimental and density functional theory simulation analysis. Appl. Catal. B-Environ. 201, 58 (2017)

64. L. Li, Y. Wang, S. Vanka, X. Mu, Z. Mi, C.J. Li, Nitrogen photofixation over III-nitride nanowires assisted by ruthenium clusters of low atomicity. Angew. Chem. Int. Ed. 56(30), 8701 (2017)

65. S. Cao, N. Zhou, F. Gao, H. Chen, F. Jiang, All-solid-state Z-scheme 3,4-dihydroxybenzaldehyde-functionalized $\mathrm{Ga}_{2} \mathrm{O}_{3}$ /graphitic carbon nitride photocatalyst with aromatic rings as electron mediators for visible-light photocatalytic nitrogen fixation. Appl. Catal. B-Environ. 218, 600 (2017)

66. Q. Liu, L. Ai, J. Jiang, MXene-derived $\mathrm{TiO}_{2} @ C / g-\mathrm{C}_{3} \mathrm{~N}_{4}$ heterojunctions for highly efficient nitrogen photofixation. J. Mater. Chem. A 6(9), 4102 (2018)

67. Y. Wang, W. Wei, M. Li, S. Hu, J. Zhang, R. Feng, In situ construction of Z-scheme g-C3N4/Mg1.1 Al0.3Fe0.2O1.7 nanorod heterostructures with high $\mathrm{N}_{2}$ photofixation ability under visible light. RSC Adv.7(29), 18099 (2017)

68. C. Li, T. Wang, Z.J. Zhao, W. Yang, J.F. Li, A. Li, Z. Yang, G.A. Ozin, J. Gong, Promoted fixation of molecular nitrogen with surface oxygen vacancies on plasmon-enhanced $\mathrm{TiO}_{2}$ photoelectrodes. Angew. Chem. Int. Ed. 57(19), 5278 (2018)

69. M. Lashgari, P. Zeinalkhani, Photocatalytic N2 conversion to ammonia using efficient nanostructured solar-energy-materials in aqueous media: a novel hydrogenation strategy and basic understanding of the phenomenon. Appl. Catal. A-Gen. 529, 91 (2017)

70. Y. Hao, X. Dong, S. Zhai, H. Ma, X. Wang, X. Zhang, Hydrogenated bismuth molybdate nanoframe for efficient sunlight-driven nitrogen fixation from air. Chem. Eng. J. 22(52), 18722 (2016)

71. L. Zhou, C.E. Boyd, Comparison of Nessler, phenate, salicylate and ion selective electrode procedures for determination of total ammonia nitrogen in aquaculture. Aquaculture 450, 187 (2016)

72. Y. Lin, H. Hu, Y.H. Hu, Role of $\mathrm{ZnO}$ morphology in its reduction and photocatalysis. Appl. Surf. Sci. 502, 144202 (2020)

73. D.Y. Kim, T. Yoon, Y.J. Jang, J.H. Lee, Y. Na, B.J. Lee, J.S. Lee, K.S. Kim, Band gap narrowing of zinc orthogermanate by dimensional and defect modification. J. Phys. Chem. C 123(23), 14573 (2019)

74. Y.J. Jang, I. Jeong, J. Lee, J. Lee, M.J. Ko, J.S. Lee, Unbiased sunlightdriven artificial photosynthesis of carbon monoxide from $\mathrm{CO}_{2}$ using a ZnTe-based photocathode and a perovskite solar cell in tandem. ACS Nano 10(7), 6980 (2016)

75. Y.J. Jang, J. Ryu, D. Hong, S. Park, J.S. Lee, A multi-stacked hyperporous silicon flake for highly active solar hydrogen production. Chem. Commun. 52(67), 10221 (2016)

76. J. Ryu, Y.J. Jang, S. Choi, H.J. Kang, H. Park, J.S. Lee, S. Park, All-in-one synthesis of mesoporous silicon nanosheets from natural clay and their applicability to hydrogen evolution. NPG Asia Mater. 8(e248), 1 (2016)

77. N.C. Kani, A. Prajapati, B.A. Collins, J.D. Goodpaster, M.R. Singh, Competing effects of $\mathrm{pH}$, cation identity, $\mathrm{H}_{2} \mathrm{O}$ saturation, and $\mathrm{N}_{2}$ concentration on the activity and selectivity of electrochemical reduction of $\mathrm{N}_{2}$ to $\mathrm{NH}_{3}$ on electrodeposited Cu at ambient conditions. ACS Catal. 10(24), 14592 (2020)

78. X. Wei, M. Pu, Y. Jin, M. Wessling, Efficient electrocatalytic $\mathrm{N}_{2}$ reduction on three-phase interface coupled in a three-compartment flow reactor for the ambient $\mathrm{NH}_{3}$ synthesis. ACS Appl. Mater. Interfaces 13(18), 21411 (2021)

\section{Publisher's Note}

Springer Nature remains neutral with regard to jurisdictional claims in published maps and institutional affiliations. 